\title{
GOING MORE PRIVATE AND SUSTAINABLE: EX-POST ASSESSMENT OF ARMENIAN WATER UTILITIES
}

\author{
N. HARUTYUNYAN \\ Department of Environmental Sciences and Policy, Central European University, Hungary.
}

\begin{abstract}
Recent worldwide changes in water policies emphasize the role of the private sector in the provision of water services with the expectation of market forces to redress public provision failures and introduce innovative approaches for promoting sustainability. Armenia has experienced unprecedented rapid and mass privatization in the water sector: in a decade from zero reaching $63 \%$ of the population, which records the third highest level in Europe. The paper examines the impacts of privatization on sustainability performance of all water utilities. Ex-post benchmarking is employed for assessing relative and absolute sustainability measures and developing scores for utility sustainability ranking. The paper focuses on utility performance in time and scale dimensions and on the international level. The paper shows that transition to the public-private partnerships positively influenced the sustainability performance of all utilities. All utilities have improved their relative to pre-privatization performance. Considerable progress was seen in social followed by environmental performance. Armenian utilities also succeed in performing well internationally. The paper concludes that though water privatization may lead to sustainability of utility performance, the scale of impact may depend on the initial state of the enterprise and the local context. Moreover, after the low-hanging fruits are reached at the first stage, more efforts will be required for enhancing long-term sustainability and effectiveness, consistent with social and environmental needs.

Keywords: Armenia, benchmarking, ex-post evaluation, infrastructure, privatization, public services, sustainability, transition, utility performance, water reforms.
\end{abstract}

\section{INTRODUCTION}

Recent water policy reforms worldwide highlight the importance of the private sector in the provision of water services and stress the prospects for sustainable development through water resource and service management strategies [1,2]. Sustainability challenges that the water sector has to tackle today and in the future include the protection of water resources (environmental dimension), security and affordability of water supply (social dimension) and operation and financing of water systems (economic dimension) [1]. Privatization as an innovative strategic management tool is being promoted for ensuring sustainability in the water sector backed by the theoretical prospective of "market conservation' [2] and reinforced by the Dublin Principles on water and sustainable development that recognize water as an economic good and emphasize market-driven approaches for sustainable water resource management [3]. Private sector involvement is believed to redress public provision failures and provide more efficient services and promote sustainability through the introduction of innovative management and technical competencies [4].

Although escalating in trend with prospects of considerable acceleration by 2025 worldwide [5], the private sector involvement is one of the most controversial issues, especially in the water sector [3]. Being appealing theoretically, in practice implementation of privatization is not as straightforward as theory suggests [6]. Contrary to past optimism, it resulted in mounting criticism [5], especially after a series of highly publicized contract terminations that raised resistance and doubts about the viability of privatization in the water sector, emphasizing the need for more empirical studies in this area [4].

The literature shows a range of studies on privatization impacts. Various aspects (e.g. cost function, efficiency and productivity) are examined and various methods are used to compare the 
performance of water utilities under various governance models [1,3]. However, studies do not lead to any sound evidence about the sustainability performance of water utilities, especially in developing and transitional economies [6]. Yet rapid and large-scale privatization has been a very significant phenomenon in the transition process from centrally planned to market systems accentuating research of privatization experiences in these countries.

The paper expands the scientific understating of the impact of privatization on sustainability performance in transition countries by focusing on Armenia that experienced unprecedented rapid and mass privatization in the water sector: within a decade from zero reaching up to $63 \%$ of the population [7]. It examines the impact of privatization on the sustainability performance of all five water utilities. It employs the ex-post benchmarking method based on comparisons across utilities along three dimensions: economic, social and environmental. The focus of the paper is on the performance of utilities in time (before and after privatization) and scale among the utilities. It also considers performance of utilities on the international level. It is important to emphasize that this is a pioneer study since some of the assessments, such as overall sustainability assessment, international comparison and ranking of water utilities are done for the first time.

The results show that transition to the public-private partnership governance models of operation positively influenced the utility sustainability performance. All utilities improved their relative to pre-privatization performance with the smallest water utility ranking the top position. Armenian utilities also succeed in performing quite well internationally: compared with the minimum international performance all utilities recorded superior performance; compared with the average international performance, some utilities managed to outperform it, whereas others were operation close to it.

\section{OPERATIONALIZING PRIVATIZATION}

Private sector participation in the provision of water services is defined as a process of transferring some public assets or functions to private companies under various contractual forms that differ in allocation of decision prerogatives, risks and revenues, rights and obligations across public and private partners. The public-private partnership model of water governance involves operation under service contracts, management and lease contracts with private firms operating the facility but not investing, concessions with private companies required to make investments, build-operate-transfer schemes or divestitures under which private companies buy some or all the equity from the state.

\section{TRANSITION TO PUBLIC-PRIVATE GOVERNANCE MODELS}

In the late 1990s, after a decade of painful transition to a free-market economy accompanied by poor repair and under-investment, the water industry appeared in a condition of an urgent need of reforms to prevent a further deterioration of the system to the point of non-repair and to improve water management. The reforms were conducted as a part of structural changes taking place since 1994 based on traditional economic policy standpoints and the financial support of international financial institutions. Commercialization of water systems was among the major components of the transformation processes in the water governance system. Private sector involvement and performance-based contracts were the novelties introduced.

By starting water sector reforms in the 2000s, Armenia had already a remarkable track record of private involvement in other sectors. There was a buildup of expertise in dealing with economic and legal aspects of privatization contracts. Despite this, the government was careful in entering into public-private partnerships in the water sector. A decision was made to take a case-by-case approach: start with a short-term management contract with the possibility of extension if the experience was successful. Although the implementation of the first management contract was not without prob- 


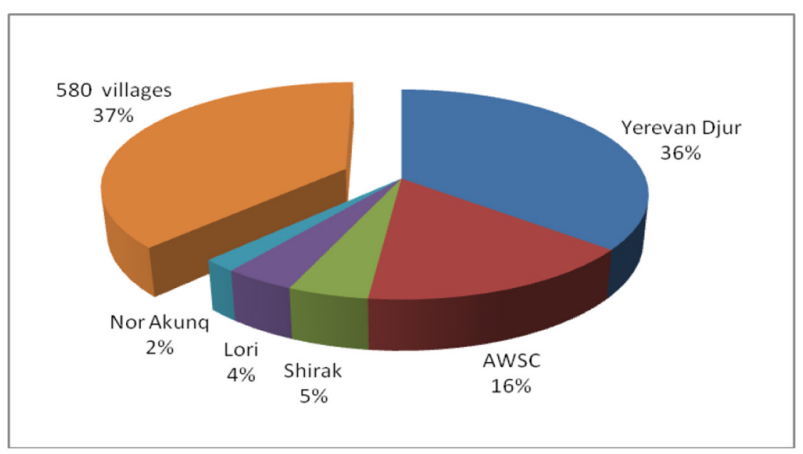

Figure 1: Population served by Armenian water utilities.

lems, it enabled to get more learning and experience to go further. Afterwards privatization in the water sector followed two directions: going deeper with privatization with the lease contract and going wider with contracting other operators for the management of other utilities [8].

The analysis of the privatization trends in the region reveals that Armenia is among the Newly Independent States, which experienced the earliest and highest rates of penetration of private sector participation in provision of water services. Currently, $63 \%$ of the population receives water services from water utilities operating under private-public partnership models (Fig. 1). Remarkably, this is the third highest level after the UK (88\%) and France (75\%) recorded in European countries [7], where on average $20.5 \%$ of the population is served through public-private partnership arrangements.

Yerevan Djur is the largest utility rendering services to capital city Yerevan and neighboring villages, serving $36 \%$ of the population in the country. Next by size is the AWSC. It provides water services to $16 \%$ of the population in urban and rural communities. The three decentralized community partnership companies - Shirak, Lori and Nor Akunq - together serve almost $12 \%$ of the population of the country in urban and surrounding rural areas. The rest of the population in 580 villages relies on their own independent systems.

\section{METHODS}

In many countries, performance measurement is an important aspect of good governance. It plays an increasing role in the evaluation of utility operation [6]. The ex-post assessment of water utility performance can be done following the benchmarking method. Benchmarking is 'a process that enables comparison of inputs, processes or outputs between institutions or within a single institution over time' [9]. Application of various benchmarking techniques in various countries in the water sector is found in Peru, Canada, Italy, and so on. [10-12]. The choice of methodological approaches with varying degrees of sophistication depends on the research objectives, data availability and practical circumstances. The major methodological challenge like with many other methods is the availability of data for pre-reform periods limiting the possibility to establish historic trends [13]. Hence, the choice of methodological approach in the research is conditioned by the lack of comprehensive historical data for earlier periods and the small number of utilities.

The study is based on the analysis of water utilities currently operating in Armenia under various contractual forms of public-private partnerships. The top-down approach is used to scrutinize 
the privatization from aggregate level, in which the utility is the unit of analysis. The study employs the ex-post benchmarking method with involvement of both the operational benchmarking that observes vertical comparisons of performances within the institution and the external benchmarking based on horizontal comparisons across multiple institutions. The focus of the paper is on the performance of utilities in time and scale among the utilities. It also assesses utility performance on the international level. Ex-post benchmarking follows two approaches for assessing the relative and the absolute measures on sustainability performance of utilities and developing scores for overall sustainability ranking among all studies' utilities. Indeed, it is the first time that overall sustainability performance and ranking has been developed for all water utilities in Armenia. The Apgar score for measuring the general health of utility operation is also developed.

Studies on utility performance point out that in case of having a big number of separate but related indicators, the performance indexing can be used as a practical management tool for aggregating various data sets into an overall sustainability measure. The advantage of using indexes rests in their ability to condense the information reflected in a great amount of variables into one number and demonstrate what is happening overall [14]. In general, there is no set procedure for producing indexes. Yet there are a number of concepts to be followed. The fundamental one is that all the indexes are architected for a certain objective, and proper indicators are selected and conjoined in a way to contribute to the purpose of the index.

The choice of the indicators in the research is guided by the basic sustainability principle that is built upon a rationale of an ecologically efficient use of natural, social and economic resources. Taking into account local circumstances, the purpose and context of the research, the selected indicators are grouped into three main dimensions:

- Economic performance: operating costs coverage, payment collection efficiency and labor productivity;

- Social performance: supply continuity, affordability and coverage;

- Environmental performance: non-revenue water, metering, consumption and energy use.

The first group of indicators presents a proxy demonstration of the financial and economic sustainability of water utilities. The second set can act as a barometer for the social performance reflecting the interest of the population. The third, environmental performance denotes the relationship between the water utilities and the environment. The indicators are further aggregated into indices and fit into larger information pyramid.

\subsection{Relative sustainability performance and ranking}

Most popular methods of estimating overall performance are based on a linear combination of weighted parameters. Employed in the paper is the performance relatives method. The relative sustainability performance index $\left(\mathrm{SPI}_{\text {rel }}\right)$ is based on performance relatives used to show the relative weight or progress in the performance of each water utility compared with its baseline (the 'before' privatization case). The average of performance relatives is calculated by using a geometric mean. It is a relative value. Absolute value of the index is meaningless and only gets its meaning when compared with the baseline. Based on this, relative ranking compares the same indicators only to each other, in contrast to fixed, absolute targets. 


\subsection{Absolute sustainability performance and ranking}

The absolute sustainability performance index ( $\mathrm{SPI}_{\mathrm{abs}}$ ) is built upon the method that derives a fixed scale matrix for the range of performance for a set of selected indicators. In the present research, a 10-level performance matrix is developed for 10 performance indicators for each utility. For each performance indicator, a relative importance (weight) and impact on the index is identified. The weights mount up to the sum of $100 \%$. The weights are selected based on logical and common sense reasoning of the research based on local knowledge of needs and priorities. The score for each performance is determined by multiplying the performance level by its weight. The composite result is derived by summing up the scores for all indicators.

The performance matrix incorporates the baseline, attainable stretch and superb goals, which are built with due consideration of various studies, best practices, country priorities, utility targets and international benchmarks. The matrix is designed with due consideration of how increase and decrease in each indicator relate to the performance. The approach to construct the baseline follows the logic of building to some extent an average minimum international performance. The same way, the stretch and superb goals are built to reflect an average high and superb international performance. The changes overtime such as comparison with the 'before' case are also calculated. The absolute performance ranking for each water utility is based on the points attained on the absolute sustainability performance measures.

\subsection{Apgar score}

Apgar score is a method developed by Dr. Virginia Apgar for estimating the health of newborn babies on five criteria. Berg and Danilenko [14] used the Apgar score for measuring the general health of water utility operation. Following the sustainability logic, the analysis covers three dimensions based on five indicators (operating cost coverage, collection efficiency, affordability, coverage and non-revenue water). The score is normalized to 10 (the maximum score). Another option could be 12 if sewage service is included in the analysis. Each criterion is assessed on a scale from 0 to 2, and the results are summed up. Afterward, utilities are categorized based on the scale of overall viability: 'critically low' for the score 3.6 or lower, 'fairly low' for the score over 3.6-7.2, and 'normal' for a score over 7.2.

\subsection{Data considerations}

The analysis employs utility data obtained from the International Benchmarking Network for Water and Sanitation Utilities (IBNET) that provides comprehensive and consistent data on many variables over time. The periods covered are the year before the utilities entered into the public-private arrangement (the 'before' case) and the last year 2010 with the last available data denoting situation after privatization (the 'after' case).

\section{RESULTS AND DISCUSSION}

\subsection{Relative sustainability performance}

The results of the analysis of relative SPI that estimates the utility progress relative to the pre-privatization period show that the maximum record of performance was reached by the Yerevan Djur with 597 points (Fig. 2). The second best performer is the smallest Nor Akunq utility with recorded 


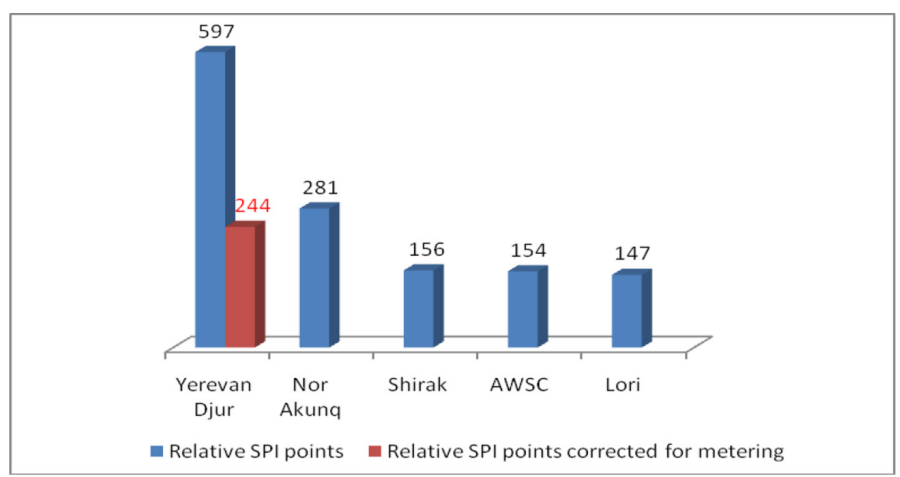

Figure 2: Relative sustainability performance.

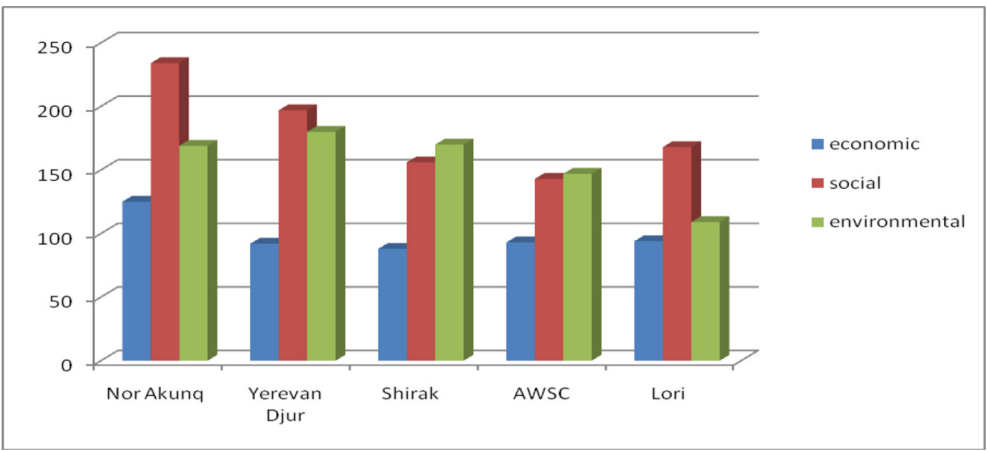

Figure 3: Split of the relative sustainability performance.

281 points of relative SPI. The other three companies have almost equal improvements in the performance. Significant difference of the Yerevan Djur record needs some clarification. First, it was the first utility to enter into a privatization contract. Second, there was a big impact of the Law on Restructuring Indebtedness (forgiveness for debts on condition of installation of metering and partial debt payment) that stimulated a large scale metering and increase of payment collection efficiency in that period all over the country regardless of water supply governance models [15]. Hence, in the analysis a correction factor for metering was introduced to present more pragmatic effects. As a result, Yerevan Djur performance declined to 244-point level, ceding the leading position to Nor Akunq.

Figure 3 presents a more detailed view on the relative performance of companies portioned by each performance dimension: economic, social and environmental. It demonstrates that considerable achievements of companies are done in relation to social performance. Next by size of progress is the environmental performance, which is led by Yerevan Djur with a score of 180 points, followed by Shirak (170), Nor Akunq (169) and Lori (109).

The study of individual indicators [8] shows that the highest contribution to the performance improvement comes from the metering, continuity of water supply and payment collection efficiency. Interestingly, being non-existent in the early 2000s, water metering by 2010 averaged 86\%, for some utilities reaching up to $99 \%$ (near universal metering), which is among the highest levels worldwide [15]. Due to the Law on Restructuring Indebtedness that stipulated debt cancelation on condition of partial debt repayment and installation of meters, collection rates reached $119 \%$ in 2003 
as compared to $20 \%$ in 2000 . This enabled water utilities to improve water quality services. Accordingly, in further assessments for recording sustainability progress more efforts for improving non-revenue, energy use and operative cost coverage will be required.

\subsubsection{Relative performance ranking}

Table 1 presents the relative performance rankings for each water utility. The ranking in the first column is based on the points attained on the sustainability performance measure. Nor Akunq with 281 points is the leader among all water utilities in sustainability performance. The next is Yerevan Djur with 244 points corrected for metering. There is also a split of sustainability performance into economic, social and environmental performances with related rankings. The best in environmental performance is still Yerevan Djur even if deflated with metering. Three companies (Yerevan Djur, Shirak and Nor Akunq) are clustered in the upper environmental performance level with significant progress in performance, whereas two companies (AWSC and Lori) are in the lower level without much difference in performance. AWSC that provides water services in large area is burdened with higher water leaks, higher costs and investment requirements, which negatively impacted its overall performance.

\subsection{Absolute sustainability performance}

Figure 4 depicts the results on the absolute sustainability performance of water utilities. An increase in value of the absolute SPI represents a decrease in performance. The pentagram diagram shows how the absolute SPI scores of water utilities can be compared with the baseline value of 700 (minimum international performance), the stretch goal of 300 (average international performance) and superb goal of 100 scores (best international performance).

First, the current ('after' privatization) performance is compared with the 'before' privatization performance. As it is seen in Fig. 4, under public-private partnership arrangements all water utilities have improved their absolute sustainability performance. Moreover, compared with the baseline in both the 'before' and the 'after' cases all the companies score superior performance. Furthermore, Nor Akunq from the initial the lowest 'before' score (590) recorded the greatest achievement in the 'after' case (240). Together with AWSC scored 290, it managed to step beyond the average international performance. The rest of utilities are operating close to it. Overall, in addition to improvement relative to pre-privatization performance, Armenian utilities succeed in performing quite well internationally. Finally, being on a good track all the companies still have a lot of room for improvement to reach the best international performance.

Table 1: Utility ranking on relative sustainability performance.

\begin{tabular}{|c|c|c|c|c|c|c|c|c|}
\hline & \multicolumn{2}{|c|}{$\begin{array}{l}\text { Sustainability } \\
\text { performance }\end{array}$} & \multicolumn{2}{|c|}{$\begin{array}{c}\text { Economic } \\
\text { performance }\end{array}$} & \multicolumn{2}{|c|}{$\begin{array}{c}\text { Social } \\
\text { performance }\end{array}$} & \multicolumn{2}{|c|}{$\begin{array}{c}\text { Environmental } \\
\text { performance }\end{array}$} \\
\hline & Rank & $\mathrm{SPI}_{\text {rel }}$ & Rank & $\mathrm{SPI}_{\mathrm{rel}}$ & Rank & $\mathrm{SPI}_{\mathrm{rel}}$ & Rank & $\mathrm{SPI}_{\mathrm{rel}}$ \\
\hline Yerevan Djur & 2 & 244 & 4 & 92 & 2 & 197 & 1 & $180^{*}$ \\
\hline AWSC & 4 & 154 & 3 & 93 & 5 & 143 & 4 & 117 \\
\hline Shirak & 3 & 156 & 5 & 88 & 4 & 156 & 2 & 170 \\
\hline Lori & 5 & 147 & 2 & 94 & 3 & 168 & 5 & 109 \\
\hline Nor Akunq & 1 & 281 & 1 & 125 & 1 & 234 & 3 & 169 \\
\hline
\end{tabular}




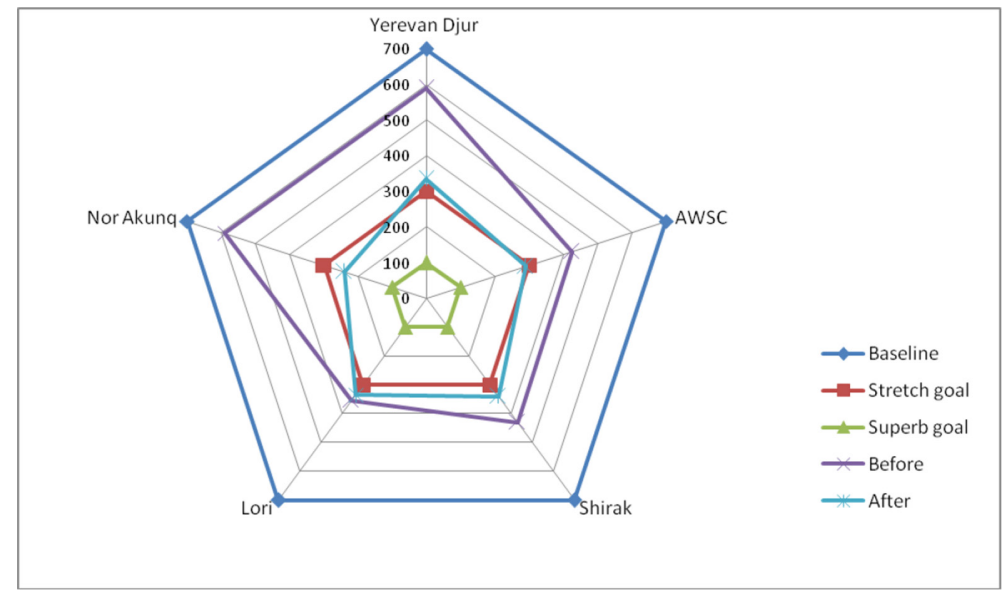

Figure 4: Water companies absolute sustainability performance.

5.2.1 Absolute performance ranking

The absolute performance rankings (Table 2) for each water utility are based on the points attained on the absolute sustainability performance measure. The ranking compares the absolute sustainability performance of all utilities to predefined thresholds: the baseline (700) and the stretch goal (300). It is important to note that the absolute ranking is different from relative ranking, which is based on the comparison with the 'before' case only. Yet absolute ranking reflects international comparisons.

Water utilities that achieved and/or outperformance the stretch goal of 300 are highlighted in green. These are the smallest and the biggest companies: Nor Akunq and AWSC, respectively. Interestingly, two bottom companies, Yerevan Djur (the biggest utility) and Nor Akunq (the smallest utility), in the 'before' case moved to the top position in the 'after' case. Steeper improvement of Yerevan Djur reflects its operation at the municipal level with higher density of connections and the poorer initial conditions on some of indicators such as metering and collection rates.

\subsection{Water utility Apgar score}

The results of the Apgar score for all water utilities show a progress in the average Apgar score between 2000 and 2010 (Table 3). Compared with the 'before' case, all the utilities, except for Shirak, moved one step up. Shirak still encounters operational cost coverage issues even on the background of significant improvement in collection. There was no utility operating in the green (normal) zone in the 'before' case. Two companies (Yerevan Djur and Lori) moved from fairly low toward performance classified as normal (marked green). At the same time, there is no more utility operating in the critically low zone as it was in the 'before' case. The scale does not matter and the smaller utilities do not over- or under-perform large utilities.

Assessing a utility performance with the Apgar score not only gives an indication of its current state. It is also an important tool for signaling water utilities about the problems to be faced in the near future and giving a good time for preventive measures. 
Table 2: Utility ranking on absolute sustainability performance.

\begin{tabular}{lcccl}
\hline Before & SPI $_{\mathrm{abs}}$ & Rank & SPI $_{\mathrm{abs}}$ & After \\
\hline Baseline & 700 & & 700 & \\
\hline Lori & 355 & 1 & 240 & Nor Akunq \\
AWSC & 425 & 2 & 290 & AWSC \\
Shirak & 430 & 3 & 335 & Lori \\
Nor Akunq & 590 & 4 & 335 & Yerevan Djur \\
Yerevan Djur & 590 & 5 & 340 & Shirak \\
\hline
\end{tabular}

Table 3: Water utility Apgar score.

\begin{tabular}{lclcl}
\hline & Apgar score & \multicolumn{1}{c}{ Before } & Apgar score & \multicolumn{1}{c}{ After } \\
\hline Yerevan Djur & 5 & Fairly low & 8 & Normal \\
AWSC & 3 & Critically low & 4 & Fairly low \\
Shirak & 5 & Fairly low & 5 & Fairly low \\
Lori & 5 & Fairly low & 8 & Normal \\
Nor Akunq & 2 & Critically low & 7 & Fairly low \\
\hline
\end{tabular}

\section{CONCLUSIONS}

Over the last decade in Armenia, unprecedented rapid and mass privatization was introduced reaching up to 63\% of the population, which is the third highest level in Europe. The paper presented the ex-post assessment of the directional and magnitude impacts of privatization on sustainability performance of all water utilities operating in Armenia under various forms of public-private partnership along three dimensions: economic, social and environmental. The benchmarking method was applied to assess both the relative and the absolute sustainability performance and ranking for all water utilities, which had never been done before. Assessment of relative sustainability that traces the performance progress of each utility over time compared with its baseline (the 'before' privatization case) shows that under public-private partnerships all water utilities achieved higher sustainability performance. The maximum progress was recorded by the smallest Nor Akunq utility, followed by the biggest Yerevan Djur utility that provides its services at the municipal level with a high concentration of customers. The other three companies attained almost equal improvements in the performance. The results of absolute sustainability performance assessment show that compared with the minimum international performance, all Armenian utilities recorded superior performance in both the 'before' and 'after' privatization cases. Furthermore, some of the companies succeed in outperforming the average international performance, while others are operating close to it. Interestingly, in the 'before' case the lowest ranked Nor Akunq utility appeared in the top position in the 'after' case.

The results of the Apgar score assessment show that compared with the 'before' case, four out of five companies moved one step up. There was no utility operating in the green (normal) zone in the 
'before' case. At the same time, in the 'after' case there is not any more utility operating in the critically low zone, while some already operate in the green zone.

What can be concluded from the study is that privatization of water utilities may lead to sustainability of utility performance, also on the international level. Moreover, under public-private partnership models both small and large scale companies can operate equally successful. However, the scale of the impact of privatization depends on the initial state of the enterprise and the local context. Furthermore, after the high return and low risk 'low hanging fruits' are reached at the first stage, more efforts will be required for enhancing the long-term sustainability and effectiveness, consistent with social and environmental needs. On the whole, utility sustainability measurement and the ranking among the utilities may be useful for comparing with and learning from others, bringing to light the performance gaps, (re)defining targets for each utility and focusing on management areas requiring priority improvements. Finally, more research is needed on studying the impacts of privatization on people using bottom-up approaches.

\section{REFERENCES}

[1] Leiberherr, E. \& Bernhard, T., The impact of privatization on sustainability transitions: a comparative analysis of dynamic capabilities in three water utilities. Environmental Innovation and Societal Transitions, 2014 [in press], http://www.eawag.ch/forschung/ess/publikationen/pdf/ Lieberherr_truffer.pdf

[2] K'Akumu, O., Sustainability prospects for water utilities privatization in Kenya. International Journal of Technology Management and Sustainable Development, 5(3), pp. 271-280, 2006. doi: http://dx.doi.org/10.1386/ijtm.5.3.271/1

[3] Ouyahia, M., Public-Private Partnerships for Funding Municipal Drinking Water Infrastructure: What Are the Challenges? Discussion paper, PRI project, Sustainable Development, 2006, ISBN 0-662-43362-9.

[4] Kirkpatrick, C., Parker, D. \& Zhang, Y., State versus private sector provision of water services in Africa: an empirical analysis. The World Bank Economic Review, 20(1), p. 143, 2006. doi: http://dx.doi.org/10.1093/wber//hj001

[5] Hukka, J. \& Katko, T., Water Privatization Revisited. Panacea or Pancake? IRC International Water and Sanitation Centre: The Netherlands, 2003.

[6] Ndandiko, C., Public Provision of Private Services in Developing Countries, PhD dissertation, University of Twente: The Netherlands, 2010.

[7] Harutyunyan, N., Alternative partnership models for water governance: a case study in Armenia. WIT Transactions on Ecology and the Environment, 191, pp. 1609-1620, 2014. doi: http:// dx.doi.org/10.2495/SC141372

[8] Harutyunyan, N., State versus private sector provision of water services in Armenia. Frontiers of Environmental Science and Engineering, 6, pp. 620-630, 2012. doi: http://dx.doi.org/10.1007/ s11783-012-0425-8

[9] Harvey, L., Analytic Quality Glossary, Quality Research International, 2004.

[10] Lin, C., Service quality and prospect for benchmarking: evidence from the Peru water sector. Utility Policy, 13, pp. 230-239, 2005. doi: http://dx.doi.org/10.1016/j.jup.2005.04.002

[11] Canadian Water and Wastewater Association (CWWA), Water Conservation and Efficiency Performance Measures and Benchmarks within the Municipal Sector, a report to the Ontario Ministry of Environment, 2009.

[12] Storto, C., Benchmarking in the public service industry: the Italian water service management sector. Paper for Conf. on the IEEE International Conference on Industrial Engineering and Engineering Management, 2011, doi: http://dx.doi.org/10.1109/ieem.2011.6118094 
[13] Foster, V. et al., Utility reforms (Chapter 3). Analyzing the Distributional Impact of Reforms, Washington, DC: World Bank, pp. 73-114, 2005.

[14] Berg, C. \& Danilenko, A., The IBNET Water Supply and Sanitation Performance Blue Book: The International Benchmarking Network for Water and Sanitation Utilities Databook, World Bank, SKU: 18582, 2010.

[15] Harutyunyan, N., Metering drinking water in Armenia: the process and impacts. Journal of Sustainable Cities and Society, 14, pp. 351-358, 2014, doi: http://dx.doi.org/10.1016/j. scs.2014.05.014 